\title{
Performance Prediction of a Turboshaft ENGINE THROUGH THE USE OF LOSSES MODELS
}

\author{
Siamak Hosseinzadeh $^{1 *}$, Ramin Ghasemiasl ${ }^{2}$, Amin Bahrami $^{3}$ \\ ${ }^{1 *}$ Department of Mechanical Engineering, West Tehran Branch, Islamic Azad \\ University, Tehran, Iran \\ Hoseinzadeh.siamak@gmail.com \\ ${ }^{2}$ Department of Mechanical Engineering, West Tehran Branch, Islamic Azad \\ University, Tehran, Iran \\ info@ghasemiasl.ir \\ ${ }^{3}$ Department of Mechanical Engineering, University of Science and Technology, \\ Tehran, Iran \\ aminbahrami87@yahoo.com
}

\begin{abstract}
The aim of present research is performance simulation of axial flow turbine by using of onedimensional modelling method. As respects the importance of modelling for performance prediction and optimization in initial designs level, in following work, that is based on one-dimensional modelling method, after the presentation of solution algorithm by trial and error method and introduction of different loss models for modelling, this method were examined for a turbo shaft engine and compared with experimental results. Comparison of the results with experimental data shows so good adaptation. Also according to these results, Kacker and Okapuu's developed model gave the closest results to the reference data.
\end{abstract}

\section{Keywords}

Modelling; Two-stage axial flow turbine; Total loss coefficient; Loss model; Performance curve

\section{INTRODUCTION}

Gas turbines have an important role in power generation and propulsion units and day to day with technology progress and increase the efficiency and performance, their utilization rises in aerospace and electricity generation plants and Power Generation systems [1].

Due to the very wide scope that exists for gas turbines, must show accurate and reliable performance in the vast range of environment temperature, pressure and also flight Mach and rotational speed.

According to flow pattern complexity in gas turbines, different calculating and modelling methods are required in order to their effective design. Meanwhile, one-dimensional modelling is a simple and fast method due to the performance prediction and optimization of initial design.

\section{Principles of One Dimensional Analysis}

One-dimensional modelling is a simple, accurate and fast method for obtaining gas turbine performance condition. In this method, the averages of aerodynamic and thermodynamic properties are considered on midstream line [2].

In this method, to simplify the equations and having a faster access to performance characteristics, the following assumptions are applied:

1-The inlet gas is considered as a perfect gas. 
2-The flow is steady.

3-Heat transfer effects are ignored.

4-The flow is one-dimensional. Therefore various parameters changes are regardless in the radial and angular direction, and the values at mean radius, are considered as the average values of the whole blade passage.

5-Since the viscosity of air changes with temperature, these changes are taken into consideration.

\subsection{One Dimensional Modelling by Using of Suggested Algorithm}

The suggested algorithm is based on flow field equation in turbine blades.

By applying the continuity equation on stator outlet section and replacement of Mach number relation in it, and by using other base equations, the dimensionless mass flow rate equation will be obtained by considering the losses term as $[1,3]$.

$\frac{m \cdot \sqrt{\frac{R T_{0}}{\gamma}}}{A_{\text {out }} P_{0}}=\sigma \cos \left(\alpha_{\text {out }}\right) M_{\text {out }}\left(1+\frac{\gamma-1}{2} M_{\text {out }}^{2}\right)^{\frac{\gamma+1}{2(1-\gamma)}}$

It can be seen that the left hand side of this equation is a function of the mass flow, m., the outlet flow area, $\mathrm{A}_{\text {out }}$, the stagnation temperature, T0, and the stagnation pressure, P0. And the right hand side is a function of the outlet Mach number, $\mathbf{M}_{\text {out }}$, and outlet flow angle, $\alpha$ out. The special symbol $\sigma$ is a function of entropy change of actual process [4]:

$\sigma=e^{(-\Delta s / R)}$

To do the calculations, rather than turbine geometry, amount of turbine rotational speed, stagnation temperature and pressure conditions of input flow to turbine are defined. Calculation will be started from turbine inlet. The solution of the flow equation through the suggested algorithm for modeling is as follows:

First, the proper Mach number is determined in blade cascade inlet. Then by using of continuity equation in turbine inlet, the mass flow rate is calculated. By guessing an initial Mach number and flow angle in blade outlet, losses coefficients and total loss coefficient will be determined by using of loss model. After determination the total loss coefficient, the only unknown parameter in the flow equation is outlet Mach number that is calculated. By calculating of outlet Mach number, the outflow angle will be modified and this repetition continued until intended precision achieved. By determining final outlet Mach number, another parameter like outlet stagnation pressure and temperature will be achieved.

Calculating the flow condition after choke, is one trait of done modeling. In blades, choking phenomenon occurs when Mach number or critical velocity ratio is equal one. For values of Mach number greater than 1.0, the outlet flow angle of the blade row is calculated by using of choking mass flow.

By using of flow equation and placement $M=1$, we reach to Eq. (3) for critical mass flow:

$m_{c r}^{\square}=\cos \left(\alpha_{\text {out }}\right) \cdot \sigma \cdot A \cdot P_{0} \cdot\left(\frac{1+\gamma}{2}\right)^{\frac{-1}{(\gamma-1)}} \cdot \sqrt{\frac{2 \gamma}{R T_{0}(\gamma+1)}}$

The critical mass flow that is calculated in Eq. (3), is the choking mass flow, that its value is constant for $\mathrm{M}>1$.

$m_{\text {choke }}=m_{c r}$ 
For calculating the outlet flow angle in choking region, the choking mass flow is used $[5,6]$ :

$$
\cos (\alpha)=\frac{m_{\text {choke }}^{\cdot}}{\sigma \cdot A \cdot P_{0} \cdot M\left(1+\frac{\gamma-1}{2} M^{2}\right)^{\frac{1+\gamma}{2(1-\gamma)}} \sqrt{\frac{\gamma}{R T_{0}}}}
$$

After calculation the Mach number, choking mass flow and flow angle, other required quantities are obtained like conditions before choke.

\subsection{Loss Coefficients}

Different energy losses that usually are considered in turbine, include profile loss, secondary loss, tip leakage loss and annulus loss. These losses in axial flow turbines are expressed in terms of loss coefficients. The loss coefficients manifested by a decrease in the stagnation enthalpy, and a variation in the static pressure and temperature, compared to the isentropic flow [7].

Enthalpy loss coefficient, entropy loss coefficient and pressure loss coefficient are three usual loss coefficients in turbines. We used the pressure loss coefficient and the enthalpy loss coefficient in our modeling, that their equations are presented in this part.

The pressure loss coefficient for stator and rotor blades is defined as [7, 8]:

$$
\begin{aligned}
& Y_{N}=\frac{P_{01}-P_{02}}{P_{02}-P_{2}} \\
& Y_{R}=\frac{P_{02, \text { rel }}-P_{03, \text { rel }}}{P_{03, \text { rel }}-P_{3}}
\end{aligned}
$$

The enthalpy loss coefficient for stator and rotor blades is:

$$
\begin{gathered}
\zeta_{N}=\frac{h_{2}-h_{2}^{\prime}}{h_{01}-h_{2}}=\frac{T_{2}-T_{2}^{\prime}}{\frac{1}{2} C_{2}^{2}} \\
\zeta_{R}=\frac{h_{3}-h_{3}^{\prime \prime}}{h_{02, \text { rel }}-h_{3}}=\frac{T_{3}-T_{3}^{\prime \prime}}{\frac{1}{2} V_{3}^{2}}
\end{gathered}
$$

The parameters and subscripts that are used in these equations are based on diagram (Temperature- Entropy) in Fig. 1. 


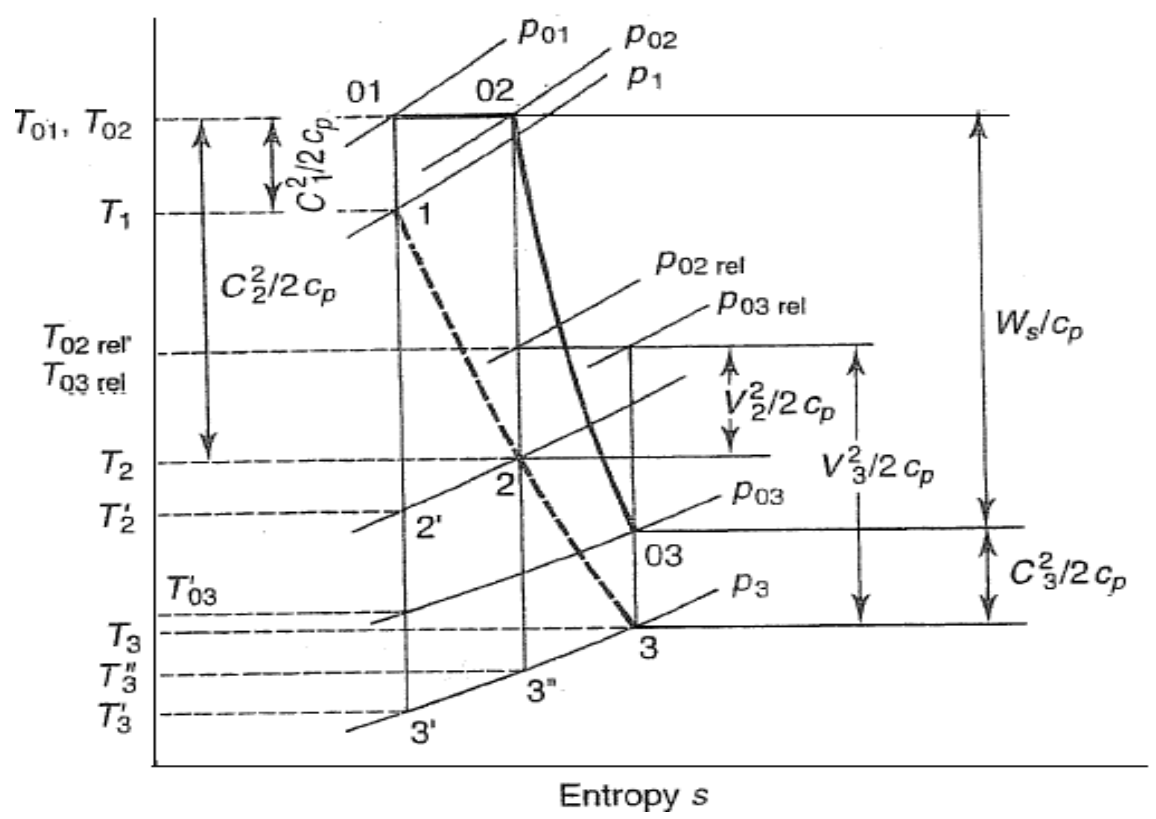

Figure 1. T-S diagram for a reaction stage [8]

There are different loss models for predicting the amount of loss in the axial flow turbines. In this section three models of these losses have been presented.

\subsection{Soderberg's model}

This model is useful for obtaining quick and preliminary estimates of turbine performance.

Soderberg gave the total loss coefficient as:

$$
\begin{gathered}
\zeta_{N}=\left(\frac{10^{5}}{\operatorname{Re}}\right)^{1 / 4}\left[\left(1+\xi^{*}\right)\left(.993+.075 \frac{l}{H}\right)-1\right] \\
\zeta_{R}=\left(\frac{10^{5}}{\operatorname{Re}}\right)^{1 / 4}\left[\left(1+\xi^{*}\right)\left(.975+.075 \frac{l}{H}\right)-1\right]
\end{gathered}
$$

In these equations, $\mathrm{H}$ is the blade height, $l$ is the blade actual chord, $\zeta$ is the enthalpy loss coefficient and $\zeta^{*}$, is the nominal loss coefficient and main function of the blade deflection. Soderberg's model only includes profile and secondary flow loss but not tip clearance loss [7].

\subsection{Kacker and Okapuu's developed model (Tournier \& Genk's model)}

This model is the latest refinements proposed by Benner et al. of Kacker and Okapuu's model and Tournier \& Genk developed it, that we used in this research.

The total pressure loss coefficient in this model is given as:

$Y=\left(Y_{p}+Y_{s}\right)+Y_{T E}+Y_{T c}$

They suggested the bottom equations for calculating profile and secondary losses: 
$\left(Y_{p}+Y_{s}\right)=\left(1-Z_{T E} / H\right) \times Y_{p}^{\prime}+Y_{s}^{\prime}$

$Z_{T E}$, is the spanwise penetration depth.

The profile loss coefficient, based on recent turbine cascade experimental data, is given by:

$Y_{p}^{\prime}=.914 \times\left[K_{i n} Y_{p, A M}^{\prime} K_{p}+Y_{\text {shock }}\right] \times K_{\mathrm{Re}}$

$K_{\text {in }}$ in Eq. (14), has a constant value and represented by different people. Also, $K_{\mathrm{Re}}$, is the Reynolds number correction factor.

The factors $\mathrm{K}_{\mathrm{p}}$ and $Y_{\text {shock }}$ in Eq. (14) is identical to that introduced by Kacker and Okapuu [9, 10] to account for the gas compressibility. Y'p,AM is the same profile loss that presented by Ainley \& Mathieson, and its equation was mentioned in previous part.

In Eq. (13), the spanwise penetration depth (ZTE) of the separation line between the primary and the secondary regions, is calculated by:

$\frac{Z_{T E}}{H}=\frac{.10 \times\left|F_{t}\right|^{.79}}{\sqrt{\cos \alpha_{\text {in }} / \cos \alpha_{\text {out }}} \times(H / l)^{.55}}+32.7\left(\frac{\delta^{*}}{H}\right)^{2}$

$\delta^{*}$, is the boundary layer displacement thickness at the inlet end wall.

In Eq. (15), the tangential loading parameter, ${ }_{t}$, is given by:

$F_{t}=2 \frac{s}{l \times \cos \phi} \times \cos ^{2}\left(\alpha_{m}\right) \times\left(\tan \alpha_{\text {in }}+\tan \alpha_{\text {out }}\right)$

In Eq. (20), ${ }^{\phi}$ is the blades stagger angle.

The secondary loss coefficient in Eq. (13), is given by:

$Y_{s}^{\prime}=F_{A R} \times \frac{.038+.41 \times \tanh \left(1.2 \delta^{*} / H\right)}{\sqrt{\cos \phi} \times\left(\cos \alpha_{\text {in }} / \cos \alpha_{\text {out }}\right) \times\left(l \cos \alpha_{\text {out }} / l_{x}\right)^{.55}}$

In this equation, $l_{x}$, is the blade chord length in rotating axial direction.

The aspect ratio factor, $F_{A R}$, is a function of the blade aspect ratio (Chord/Height).

In this model trailing edge loss coefficient, $Y_{T E}$, is a function of outlet Mach number and kinetic energy loss coefficient in trailing edge that their equations are presented by Kacker \& Okapuu [9].

Also the tip leakage loss coefficient, ${ }^{Y_{T l}}$, is calculated by using the approach of Yaras and Sjolander 
The Abstract section begins with the word, "Abstract" in 13 pt. Times New Roman, bold italics, "Small Caps" font with a 6pt. spacing following. The abstract must not exceed 150 words in length in 10 pt. Times New Roman italics. The text must be fully justified, with a 12 pt. paragraph spacing following the last line.

\section{RESULTS AND DISCUSSION}

In order to have a better understanding of a two stage axial flow turbine, behaviour and verify the suggested algorithm accuracy, modelling has been done on this engine by using of two different loss model. Experimental data have been obtained from Ref. [12]. Also turbine blades geometry has been measured by authors.

Figs. 2 and 3 show variation of the turbine mass flow versus pressure ratio at design speed. The design speed is $38100 \mathrm{rpm}$ for compressor turbine (First Stage turbine) and $33000 \mathrm{rpm}$ for power turbine (Second Stage turbine). The conditions are the same as the experiments. The comparison of achieved results of modelling with experimental results shows that the theoretical values agree with the experimental values and good adaptation exist between these results.

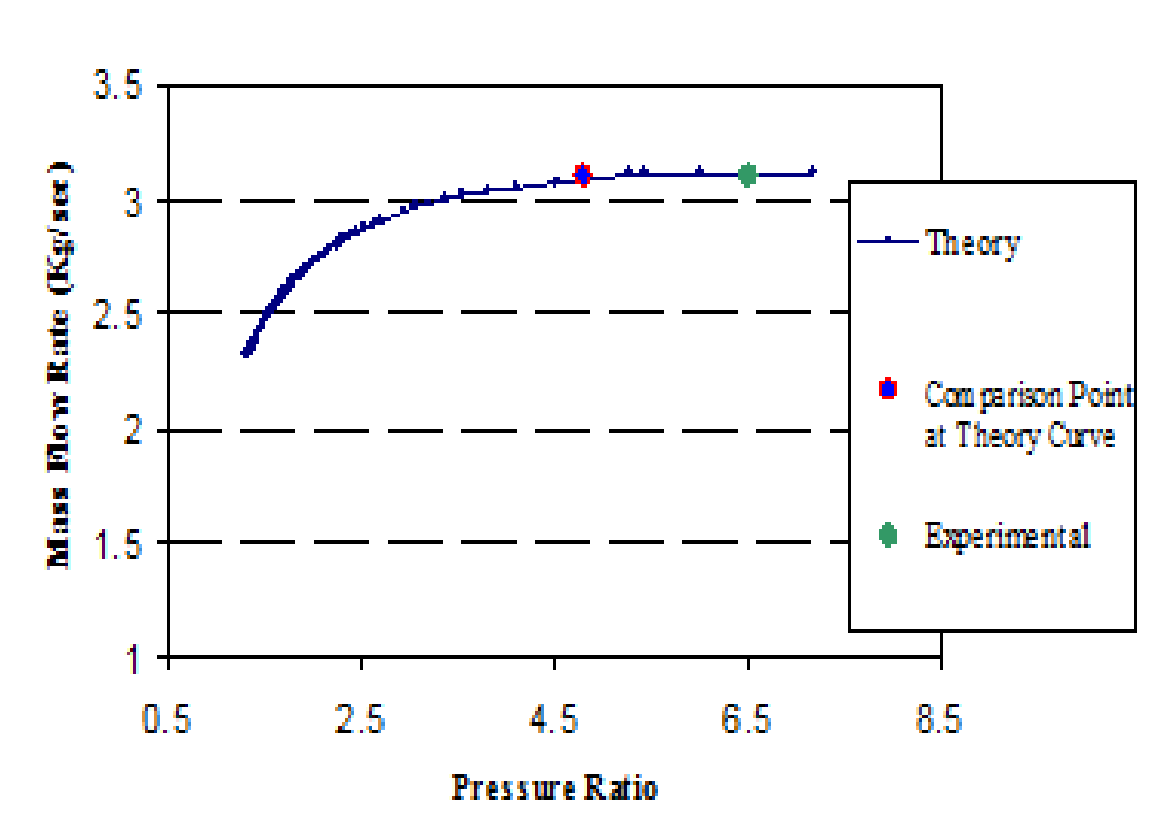

Figure 2. Mass flow vs. Pressure ratio by using of Kacker and Okapuu's developed model 


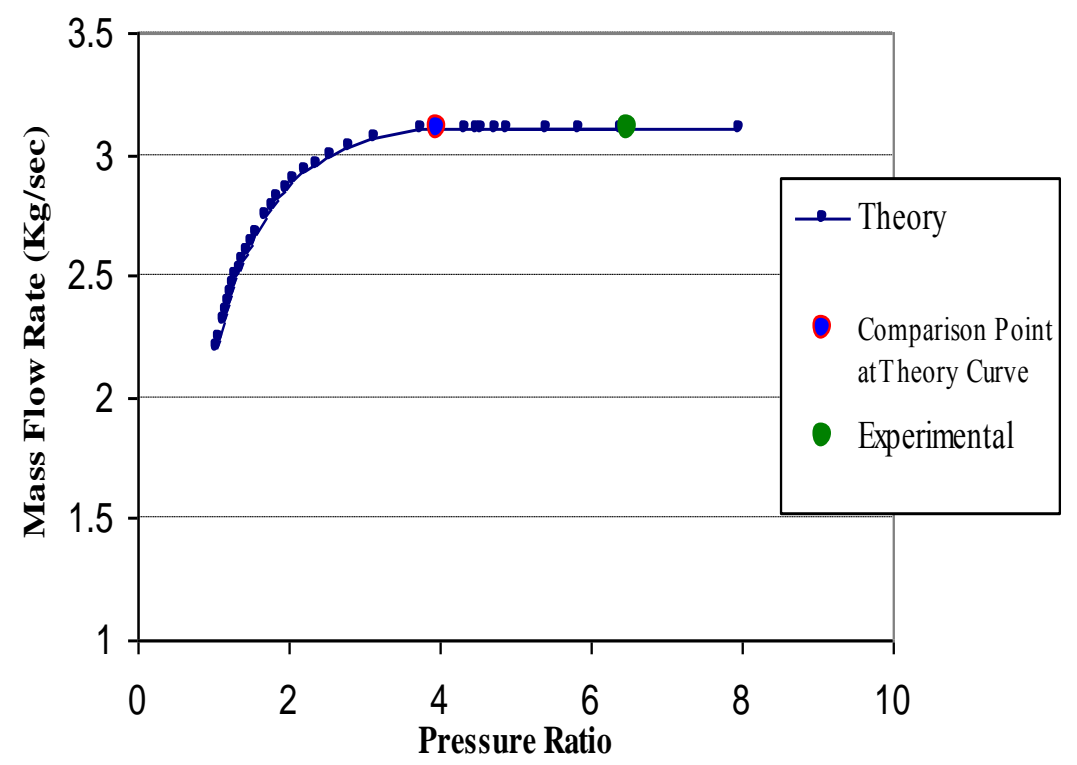

Figure 3. Mass flow vs. Pressure ratio by using of soderberg's model

In Figs. 4 and 5 efficiency curves of modelling were brought in design speed. Efficiency rises as increase of pressure ratio until it reaches its maximum measure. The reason for these changes is that in special cases, the incidence angle and energy losses due to it, reach its minimum value, so that in this condition the efficiency will maximize, and after this condition, the losses will increase again.

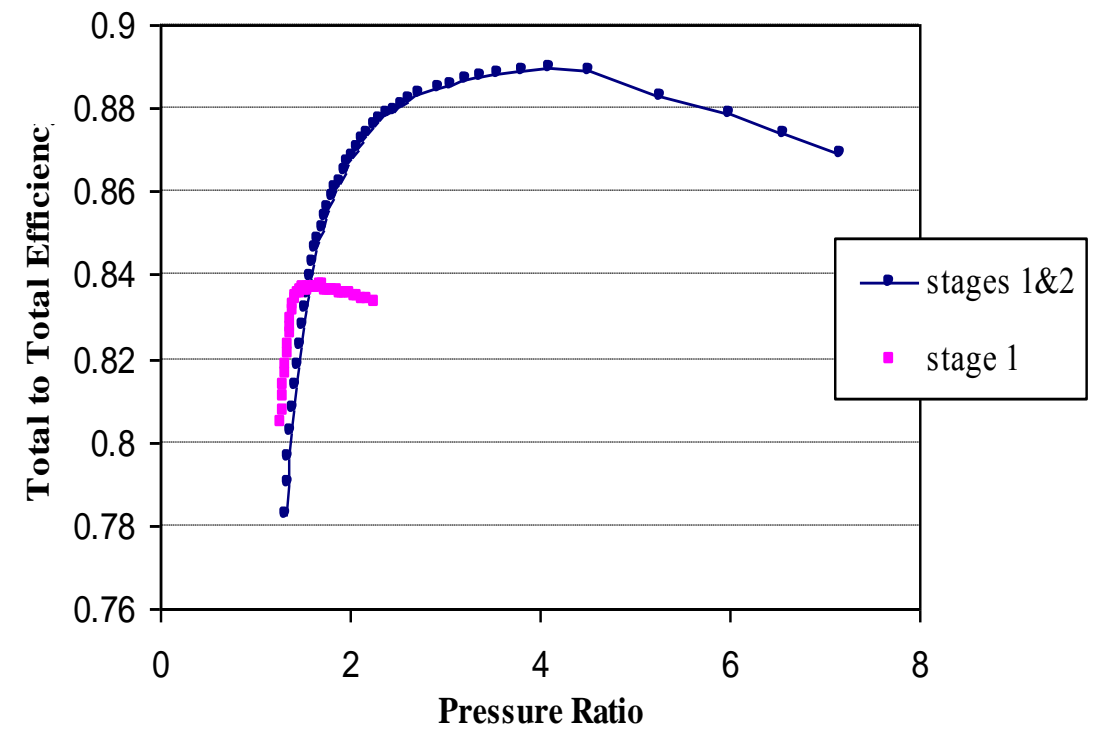

Figure 4. Turbine efficiency vs. Pressure ratio by Kacker and Okapuu's developed loss model 


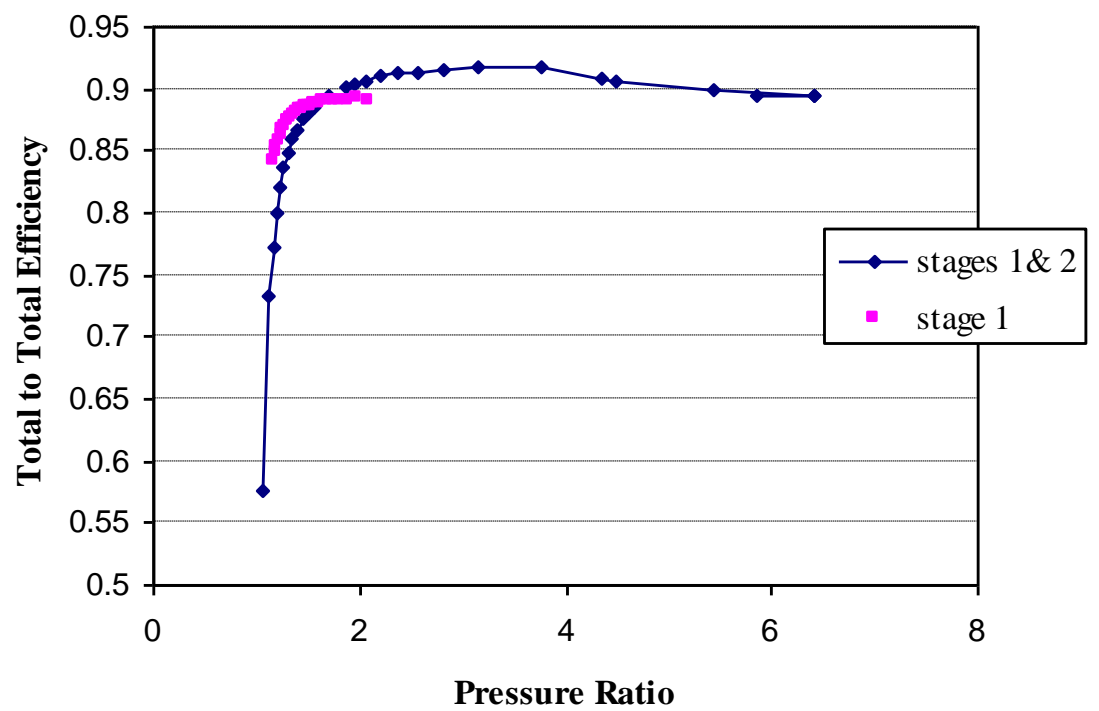

Figure 5. Turbine efficiency vs. Pressure ratio by Soderberg's loss model

In Figs. 6 and 7 the losses predictions have been shown. Fig. 6 is related to power turbine rotor blade and Fig. 7 is related to power turbine stator one.

In these Figures distribution of the profile loss, secondary loss, tip leakage loss, trailing edge loss, shock wave and total loss coefficient are presented. When the pressure ratio rises, the profile loss and total loss coefficient decrease and reach to a minimum point, and from there begin to increase again. But the Secondary loss, tip leakage loss and trailing edge loss almost exhibit linear behaviour. Also this behaviour reported by Ning Wei [7].

The profile loss has greatest value among another losses coefficient. The value of this loss, which is calculated with Eq. (14), give the lowest value near the pressure ratio 2.54 that this pressure ratio is related to about zero incidence.

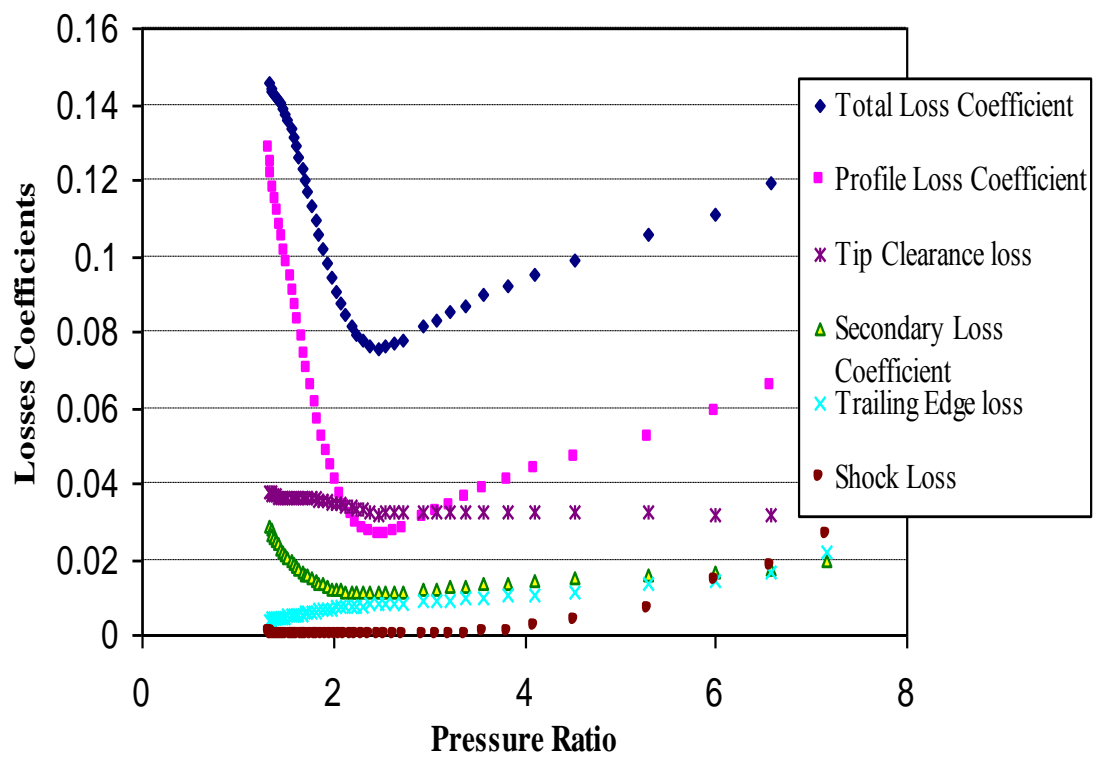

Figure 6. Loss coefficients vs. Pressure ratio 


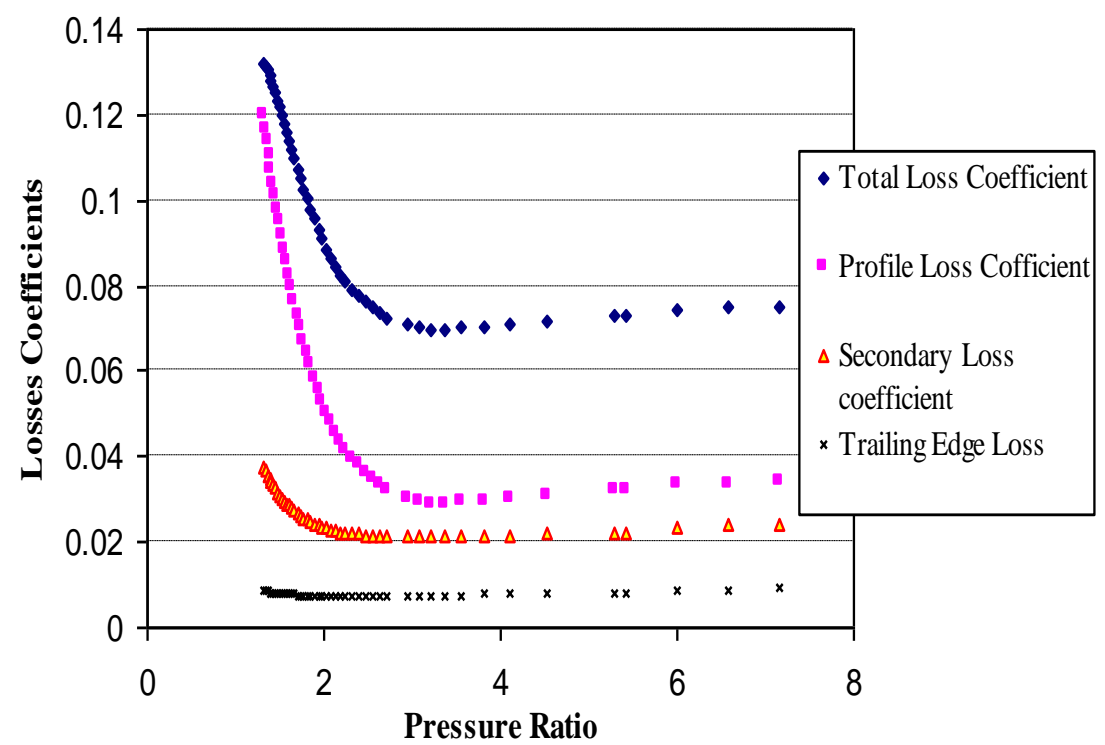

Figure 7. Loss coefficients vs. Pressure ratio

In Fig. 8 Enthalpy loss coefficient is shown for rotor and stator of power turbine. As can be seen the measure of this loss for stator blade is greater than rotor blade. This is because, according to Eqs. (10) and (11) the enthalpy loss is a main function of the blade deflection.

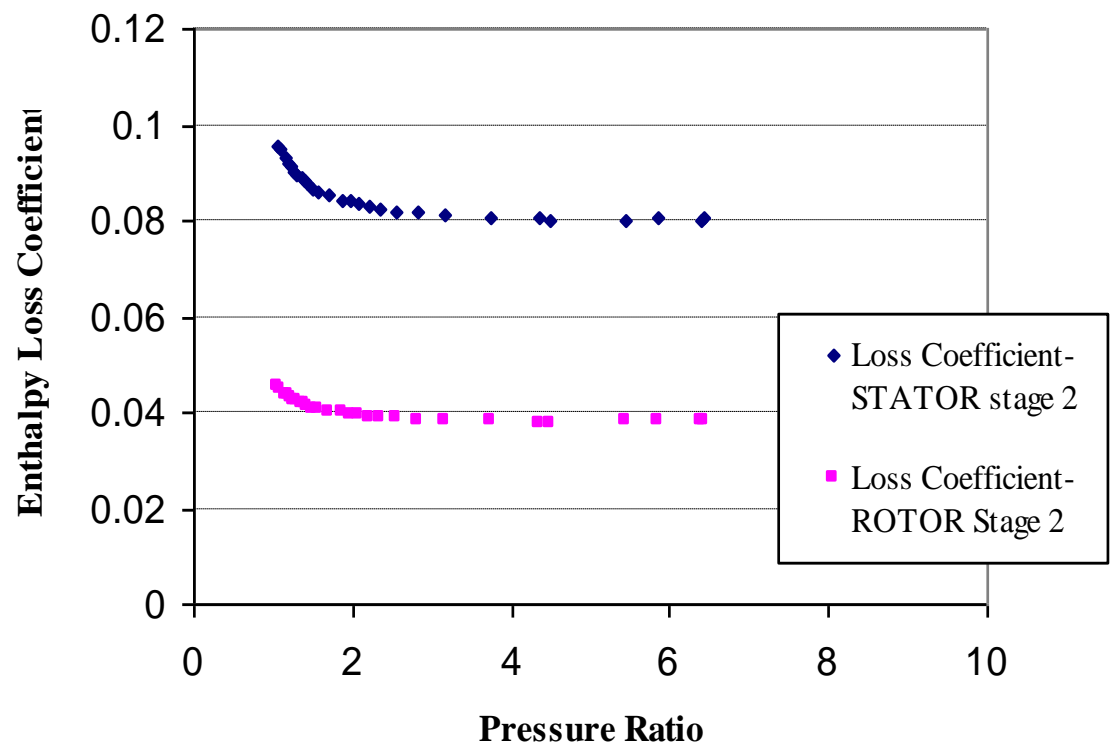

Figure 8. Loss coefficients vs. Pressure ratio

In Table 1 a comparison between outlet pressure and temperature from turbine blades and experimental data are presented. 
Table 1. Comparison between outlet pressure and temperature in theoretical and experimental Results

\begin{tabular}{|l|c|c|c|c|}
\multicolumn{1}{c|}{} & First Stage at 38100 rpm & \multicolumn{2}{c|}{ Second Stage at 33000 rpm } \\
\hline & Pout(Kpa) & Tout(k) & Pout(Kpa) & Tout(k) \\
\hline Experimental Data & 282.6 & 1058.15 & 111.00 & 901.15 \\
\hline soderberg's loss model & 302.8 & 1077 & 171.2 & 924.7 \\
\hline $\begin{array}{l}\text { Kacker and Okapuu's } \\
\text { developed loss model }\end{array}$ & 278 & 1070 & 124 & 866 \\
\hline
\end{tabular}

\section{Concluding Remarks}

In this paper, one-dimensional modelling was done by using of suggested algorithm and different loss models on a typical two stage axial flow turbine, in order to validate the suggested method and loss models. According to the results of modelling, it is clear that this modelling and suggested algorithm, predict the turbine performances acceptably.

Comparing the results of these models show that Kacker and Okapuu's developed model gave the closest results to the reference data because this model estimated the loss coefficients with greater accuracy.

\section{REFERENCES}

[1] Schobeiri M., Turbomachinery Flow Physics and Dynamic Performance, Texas A\&M University, 2005.

[2] Klepper J., Technique to predict stage-by-stage, Pre-Stall compressor performance characteristics using streamline curvature code with loss and deviation correlations, MS Thesis, University of Tennessee, Knoxvill, 1998.

[3] Rao S.S. and Gupta R.S., Optimum design of axial flow gas turbine stage , part I: Formulation and analysis of optimization problem, ASME, journal of Engineering for Power, vol. 102, pp.782-789, 1980

[4] Whitfield A. and Baines N.C., Design of radial turbomachines, Impeial college of science, London, 1990

[5] Wasserbauer C.A. and Glassman A.J., Fortran program for predicting off-design performance of radial inflow Turbines, Nasa Report, D 8063, 1975.

[6] Glassman A.J., Turbine design and application, Nasa Report, N 95-22341,1994.

[7] Ning Wei, Significance of loss models in Aero thermodynamics simulation for axial Turbines, Doctoral Thesis, Royal Institute of Technology, Sweden , 2000.

[8] Cohen H., Rogers C. and H.Saravanamutto, Gas Turbine Theory, Longman group ,1996.

[9] Tournier J.M. and Genk M., Axial flow multi-stage turbine and compressor models, Journal of energy conversion and management, Vol. 51, PP.16-29, Elsevier 2009.

[10] Dahlquist A.N., Investigation of Losses Prediction Methods in 1D for Axial Gas Turbines, MS Thesis, Lund University, Sweden, 2008.

[11] Yaras M.I. and Sjolander S.A, Prediction of tip-leakage losses in axial turbines, Journal of Turbomachinary, Vol. 114, PP. 204-10, 1992.

[12] Deport Maintenance Work Requirement for Engine, Aircraft, Turboshaft Iran T400-WV-402, IRANIAN GROUND FORCES, AUGUST 1975. 


\section{Authors}

Samak. Hosseinzadeh was born in August 22nd 1985 in Sari,Mazandaran. He received his Ms. degree in mechanical engineering (Energy Conversion) from South Tehran Branch in 2010. He also received his BSc degree in thermal fluids from Islamic Azad University Sari Branch, Mazandaran in 2007. He did his military service in Manufacturing, Mining and Trade organization as an industry expert from 2010 to 2012. He is currently a university lecturer in Islamic Azad Universities in Mazandaran, Iran. The teaching courses included Mechanical technology, Automotive and Machinery, Power Plant Technology, Installation Technology, Chemical Industry, Architecture, Power Electronics, Project Management and Executive Management. He also was a Technical Office Manager (Head Office) in Nogostaran Construction Installation Company in Tehran from 2007 to 2011. He is a member of Iran Construction Engineering organization

Doctor Ramin Ghasemi is a faculty member of Islamic Azad University, Department of Mechanical Engineering, West Tehran Branch, Islamic Azad University, Tehran, Iran. He received his Doctorate degree in mechanical engineering (Energy Conversion) from Tarbiat Modares University, Tehran,Iran. He is assistant professor. The teaching courses includes CFD, CONDUCTION, CONVECTION, RADIATION, AERODYNAMIC ,.. for PHD students.

Amin. Bahrami was born in September 22nd 1986 in Gorgan, Golestan. He received his MS. degree in mechanical engineering, Energy conversion From Iran University of Science and Technology in 2010. He also received his BSc degree in thermal fluid from Azad Islamic University Sari Branch, Mazandaran. He did his military service in Organization of School Renovation, as a mechanical engineering expert from 2010 to 2011 . He is currently university lecturer in Islamic Azad Universities in Golestan, Iran. Also, he is an employer in Organization of School Renovation. He is a member of young researchers club in Iran and Iran Engineering Organization Structure too. Hi was chosen as the top student at the Iran University of Science and Technology in 2010 and as an undergraduate student, he was

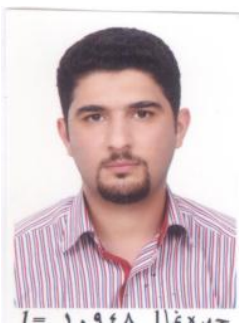
elected second. 